\title{
It matters who shares and who reads: persuasive outcomes of location check-ins on Facebook
}

\author{
Hyang-Sook Kim* and Mun-Young Chung \\ Department of Mass Communication and Communication Studies, Towson University, \\ 132 Stephens Annex, 8000 York Road, Towson, MD 21252, USA \\ Email: hkim@towson.edu Email: mchung@towson.edu \\ *Corresponding author
}

\begin{abstract}
Despite an emerging trend of location check-ins as a means of mobile communication amongst Facebook users, little attention has been devoted to the value of location check-ins as marketing potential. In particular, little is known about how mobile users process and assess location information shared by their friends on Facebook. Undergirded by persuasion knowledge and elaboration likelihood models, a self-instructed online survey with 255 undergraduate students found that friendship tie strength was positively correlated with students' attitudes towards and perceived credibility of the location information shared by their Facebook friends. However, this relationship was true of those who reported a high level of mobile phone competence rather than those with low mobile phone competence. Prior experience with location sharing on Facebook was also positively correlated with students' evaluations of the location information. Theoretical and practical implications were discussed.
\end{abstract}

Keywords: elaboration likelihood model; Facebook check-ins; friendship ties; location-based information sharing; mobile phone competence; persuasion knowledge model.

Reference to this paper should be made as follows: Kim, H-S. and Chung, M-Y. (2018) 'It matters who shares and who reads: persuasive outcomes of location check-ins on Facebook', Int. J. Mobile Communications, Vol. 16, No. 2, pp.135-152.

Biographical notes: Hyang-Sook Kim (PhD) is an Assistant Professor in the Department of Mass Communication and Communication Studies at Towson University. She earned her doctoral degree in Mass Communication from the College of Communications at the Pennsylvania State University in 2012, focusing on health and strategic communication and the psychological effects of new media technology. Her current work in new media technology explores online users' perceptions, particularly as they inform individuals' tendency to share information online.

Mun-Young Chung $(\mathrm{PhD})$ is an adjunct faculty member in the Department of Mass Communication and Communication Studies at Towson University. He earned his doctoral degree in Mass Communication from the College of Communications at the Pennsylvania State University in 2016. His research interests centre on psychological effects of media entertainment on meaningful media experience, especially nostalgia. 
This paper is a revised and expanded version of a paper entitled 'The effects of relationship tie on perceived credibility of location check-in information on Facebook', presented at the International Communication Association, San Juan, Puerto Rico, May 2015.

\section{Introduction}

Mobile communication has become a vital element of the lifestyle within the millennial generation (those whose ages range from 18 to 29), particularly those who are apt to use technology and are constantly connected with others via online social networking sites (Pew Research Center, 2010). In this population of tech-savvy mobile nomads, checking in at locations has become a trend of mobile behaviour (Pew Internet Research, 2013), especially on Facebook via the tagging function called 'Check In'. As this particular mobile communication behaviour has become popular, a growing body of literature has investigated the effects of personality traits, cultural orientations, types of businesses, motivations to facilitate the behaviour and privacy concerns on the likelihood of engaging in location check-ins (Chang and Heo, 2014; Lindqvist et al., 2011; Pontes et al., 2012; Wang and Stefanone, 2013; Waters and Ackerman, 2011). These previous studies suggest that people share their locations as a means of showing-off where they are and, thus, who they are (Wang and Stefanone, 2013). In addition to this self-presentation motivation of location check-ins, people also perceive this behaviour as a collective contribution: they are spreading the word about their pleasant experiences with their locations for the benefit of their Facebook friends. Therefore, there is a connection between the behaviour of location check-ins and electronic word-of-mouth (eWOM; Kim, 2016). The literature also suggests that the location check-in behaviour is not closely tied to privacy concerns when it occurs on Facebook, a place in which people share information mostly with their friends only and therefore feel comfortable with the information sharing (Kim, 2016; Waters and Ackerman, 2011). In particular, when people perceive that they will gain benefits from the platform of sharing information (e.g. building and maintaining social relationships through Facebook), they are willing to trade private information like their real-time locations for these benefits (Chang and Heo, 2014).

The previous literature has started explaining the psychological mechanisms and user motivations involved in location check-ins by asking why people share their location information. Yet little attention has been devoted to the value of location check-ins as marketing potential. A few studies provide surface-level information about location check-ins as business-related user behaviour; they show, for instance, that most of the places at which people check in are businesses - transportation services, scenic areas, hotels and so on (Noulas et al., 2011). In fact, many businesses have been encouraging their customers to share the business location with Facebook friends by offering discounts for such information sharing (Dhar and Varshney, 2011). The typical display of Facebook Check In is the name of a business with star ratings automatically accumulated by Google reviews in addition to a short reflection on the place made by a Facebook user. Because of Facebook users' strong motivation to broadcast pleasant moments of their lives, it is assumed that the location information that the users share on their Facebook feeds is likely to pertain to positive experiences rather than negative experiences (Jeong and Jang, 2011).

From a message recipient's perspective, exposure to a location at which his or her friend checked in on Facebook, although simple and instant, could operate as an initiative of information processing. However, the positive experience with a location shared by Facebook users might not automatically translate to positive responses to the location information amongst the users' friends on Facebook. For instance, the previous literature found that close friends showed more positive attitudes towards the advertisement campaign message shared on Facebook than distant friends (van Noort, Antheunis and Reijmersdal, 2012). When the friends of the Facebook users see the location information, how do they process this information? Will they still perceive the information in a positive light even when the information is too brief to contain the details of the location? Guided by the persuasion knowledge model (PKM; Friestad and Wright, 1994), the present study primarily 
aimed to examine the relationship between the tie strength in the form of friendship between Facebook users and the perceived credibility of the location information shared on Facebook.

\section{Literature review}

\subsection{Location-based information sharing as electronic word-of-mouth}

Explications of location-based information sharing (LBIS) emerge from two lines of the literature. One approaches LBIS by investigating the user psychology of communication technology. With a focus on impression management, LBIS not only caters to users' need for self-presentation but also expands their offline lifestyle to their online lives or seamlessly glues them together for a smooth transition between the two in a technology-saturated life (Wang and Stefanone, 2013). This line of research focuses on the psychological benefits to the user who shares his or her location via Check In on Facebook, which does not significantly resonate in the nature of information sharing over the course of the LBIS behaviour.

The other explication of LBIS taps into the outcome of the LBIS as an action of sharing (Kim, 2016). Using the original and technical definition of location-based services, "a subset of web services meant to provide functions that are location-aware, where the use of such services is predicated on the knowledge of where the services are engaged" (Wilson, 2012, p.1267), the approach of information sharing about locations used in Facebook Check In can be considered another form of eWOM. Like online reviews, photos and a wide range of digital artifacts shared in online communities (Hennig-Thurau et al., 2004; Nov, Naaman and Ye, 2010), location information that contains users' instant and minimal reviews could operate as evaluative pieces that are part of community knowledge and influence community users' perceptions of the location.

Thus, the latter explication of LBIS underscores the impact of LBIS on message recipients' information processing. In fact, eWOM has been evidenced as potentially being cost-effective advertising (Petreascu and Korgaonkar, 2011), presumably because of its nature as consumer-initiated, voluntary knowledge. In this sense, viral communication made in various online platforms, including social media, plays a key role in one's decision-making processing for product purchases (Gruen, Osmonbekov and Czaplewski, 2006). In addition, technology expedites this information-sharing process amongst consumers (Jansen et al., 2009). The recent literature has further demonstrated the importance of tie strength to the impacts of eWOM on consumers' purchase-related attitudes and behaviour, in light of the influence of relationship tie strength on advertising effects in an eWOM context and considering that strong ties play a critical role in the development of positive attitudes towards information and the purchase decision-making process (Brown, Broderick and Lee, 2007).

It must be noted, however, that the personal and social space of Facebook points to the unique nature of information sharing associated with users' experiences with businesses. Unlike the general eWOM typically found in e-commerce websites or online forums, which are open to anyone, locations shared by Facebook users are normally limited to the friends within the user's defined interpersonal network. In this case, if the location information on Facebook appears as an information source that possibly influences Facebook friends' evaluations of the location, what would be the psychological mechanisms that underlie this cognitive processing of the location information?

\subsection{The effects of tie strength on information evaluation}

It is evident that online reviews shared by previous consumers exert persuasive effects on potential consumers' cognitive processing involved with purchase decisions (Baek, Anh and Choi, 2012). In particular, when community bonding is stable and solid, the power of online reviews is especially strong (Brown, Broderick and Lee, 2007). The PKM (Friestad and Wright, 1994) provides a theoretical rationale for the relationship between the strong tie amongst community users and the positive influence of online reviews shared in the community. 
According to the model, agents (e.g. advertisers, salespersons) and targets (e.g. consumers) develop persuasion knowledge by sharing persuasion episodes that pertain to interactions between the agent and target with regard to the agent's persuasion attempts. Persuasion tactics are key to the agents' appeals to the targets, which are conveyed through persuasion attempts, whilst the targets develop attitudes towards the brands through their evaluations of the agents' persuasion attempts (i.e. coping behaviour) (for details of the model, see Friestad and Wright, 1994).

Whilst persuasion targets utilise a wide range of their prior experiences with agents' persuasion attempts, they respond to those persuasion attempts differently depending on how they interpret the meaning of the attempts. When the targets find specific intentions of the persuasion attempts by activating their persuasion knowledge (i.e. apparent evidence of commerciality and business purpose), they respond to the persuasion attempts negatively, which is also true of the online environment of advertising (Xu, 2014). Therefore, the visibility of identifiable agent information or persuasion attempts generally hurts persuasion effectiveness. However, the promotional intentions of persuasion attempts could be masked by means of eWOM. If a target is not able to easily detect promotional aims carried through a persuasion attempt in the form of eWOM because the immediate source of the attempt is already well known to the target, the coping behaviour of the target will not necessarily follow, so effective persuasion can be anticipated.

The positive influence of friends or other familiar information sources on persuasion has been well documented (van Noort, Antheunis and Reijmersdal, 2012). Specifically, previous studies found support for the prediction of a see-saw relationship between persuasion intent and persuasiveness following the core principles of PKM (Chang, Chen and Tan, 2012; Karimi and Yetkaei, 2015; van Noort, Antheunis and Reijmersdal, 2012). When an advertisement message in an example of viral marketing was disseminated through the Facebook Message feature, the perceived closeness of the Facebook friend who sent the message decreased the promotional intention; hence, the friendship tie increased the actual persuasiveness of the campaign (van Noort, Antheunis and Reijmersdal, 2012). This positive influence of the friendship tie on the viral marketing via social media could be found especially when the advertisement focused on inexpensive, entertaining products or services instead of products that required Facebook users' serious evaluations due to the high risk of that type of purchase decision (Chang, Chen and Tan, 2012).

Using the environment of Facebook, Xu (2014) investigated the effects of the relationship strength and persuasion intent on the effectiveness of Facebook advertisements by applying PKM. In particular, the study attributed the effect of the tie strength to the function of source credibility, as it found a positive effect of the strong tie on the perceived credibility of the information source. The style of sharing the advertisement information was also critical to the intention to forward the advertisement depending on the degree of tie strength, such that the strong tie increased the forwarding intention only when the advertisement was shared publicly rather than privately. The findings from this study suggest that the information shared on social media domains like Facebook must not only follow firm interpersonal bonding with the information source but also be shared publicly, instead of being shared exclusively with specific users in the community of one's social network, in order to articulate the absence of persuasion intent in the advertisement information.

For the case of the information as a result of LBIS on Facebook, persuasion intent is highly disguised because of the form of the information. Unlike other advertisements on social media platforms, location information tagged by Facebook users is simple and succinct, with minimal nuances to suggest that it is an advertisement. As it is evident that the power of friendship strength leads to positive evaluations of the advertisement shared by Facebook users (Xu, 2014), it is likely that locations tagged on Facebook by close friends, rather than distant, would also be effective in terms of the positive evaluations of the location information. Moreover, Xu (2014) focused on the perception of the information source rather than the information itself by measuring the perceived credibility of the source along with the forwarding intention for the advertisement. In other words, advertisements shared by Facebook friends are still perceived as advertised information prepared by another 
source other than the friends, who simply passed the information along. For the location information, however, the credibility is directly tied to the information itself, since Facebook users who read the location information regard their friends as the source of the information without associating the information with a promotional attempt made by the business at that location.

Credibility has been explicated as a chief concept of information processing and decision-making (Wathen and Burkell, 2002). Credibility is conceptualised with multiple layers of cognitive evaluations, such as believability, expertise, and trustworthiness (Fogg, 1999). Typically, these three evaluative components come into play when a focus of credibility points to a source of information. In particular, "experienced credibility" is considered critical to one's credibility judgment, as it is formed from one's direct experience with a source (Wathen and Burkell, 2002, p.135). In this sense, from the perspective of users who read location information shared by their friends on Facebook, the information would be considered credible when the relationship with the friends is close because of their direct experience with the source. In other words, it is plausible that source credibility established based on one's experiences could transfer to information credibility when the information originates from a highly credible source.

According to the elaboration likelihood model (ELM), positive evaluations of information are likely to occur via instant judgment led by source cues (e.g. an attractive, expert, credible source) as well as triggered by available heuristics associated with those source cues in a message recipient's mind (Petty and Cacioppo, 1986). In other words, location information shared by close friends would be perceived as more credible when Facebook users consider the friends who shared the location information to be credible and when quick association occurs between the person who tagged the location on Facebook and the information credibility. Furthermore, people tend to use a cognitive shortcut for information processing when cues of the information source are given under a relatively low-involvement condition (Petty and Cacioppo, 1986). For instance, when users believe that a source of location information is credible because the source is their friend, especially a close friend, they rely on the source cue more than the information itself to form an attitude towards the information (or the location itself). This prediction would be typical because the users are not likely to develop any interest in the location, and might not even know of the location, until they see the check-in posting by their friend.

The cue-rich environment of the online space makes easy, quick reference to information credibility available in various forms of source cues, such as source expertise (e.g. a high level of membership badge like "guru" compared to "junior") or information popularity (e.g. star ratings in a product review) (Sundar, 2008). However, the absence of such cues in the presentation of location information via check-ins on Facebook would instead give more weight to the source itself, leading to the effect of the source cue on persuasion at a great degree. In fact, Facebook users check in at locations when they want to show off their presence at special, popular places (Wang and Stephanone, 2013). This motivation for self-expression is likely to be connected to positive experiences with the location rather than negative (Jeong and Jang, 2011). Therefore, users who see the tagged locations by their Facebook friends would likely perceive the location in a positive manner as well. Indeed, Karimi and Yetkaei (2015) tested the principle of PKM for the specific mobile communication behaviour of sharing location information (using Foursquare as the information-sharing platform). They found consistent results for the positive effects of friendship tie strength on location evaluation.

H1: The greater the friendship strength, the greater the perceived credibility of the location information (Hla) and the more positive the attitudes towards location information (H1b) shared by friends on Facebook will be.

2.3 The effects of individual differences in mobile communication on evaluations of tagged locations on Facebook: prior experience with LBIS and mobile phone competence

Although the popularity of the social behaviour of location check-ins is growing amongst the millennial 
generation, there is still a gap between mobile users who check in at locations on Facebook and those who do not (Pew Internet Research, 2013). One of the common factors that makes a difference in one's information processing is knowledge, as a lower level of knowledge is likely to accelerate the cue-dependent processing (i.e. peripheral-route processing) compared to a higher one (Petty and Cacioppo, 1986). In the case of location checkins, two primary areas of knowledge about this particular technology would come into play: a prior experience with checking in at locations via mobile devices or the Facebook platform and mobile phone competence.

Previous studies that applied the ELM evidenced that relevant knowledge of a task for information processing or familiarity with the task might change the likelihood of a cursory judgement on the information using the cues available (Kim, Kim and Besley, 2013; Yang, Kim and Yoo, 2013). On one hand, distribution of one's cognition into two different areas of processing — information and task - might decrease the positive effect of cues on one's perceptions of information credibility because of the dissipation of concentration on the information as a result of allocation of cognitive capability. For instance, Yang, Kim and Yoo (2013) found that people who were willing to adopt mobile technology in their lifestyle showed a greater level of positive attitude towards mobile advertisements. This relationship, however, was no longer valid amongst those who were not used to mobile technology. Similarly, Yoo (2009) found that participants who were aware of the persuasion intent of advertisements presented after a keyword search were less likely to click on those advertisements, and this result was more pronounced when the instructions for the search were complex than when those instructions were easy to follow. This finding implies that a skill set or knowledge of the use of technology would come into play as a cognitive accelerator of cue-dependent processing in evaluating the advertisement information in a positive fashion. On the other hand, it might also be plausible that one's knowledge about the information could deter the activation of cue-dependent processing, which will result in a different evaluation of the information depending on the quality of the information. Kim, Kim and Besley (2013) found that the more educated deliberated upon the decision-making process more than the less educated for support of genetically modified food rather than using information shortcuts such as personal predispositions of ideology and religion as well as general public consent to the topic.

In the specific context of LBIS, the recall of location information is accurate amongst those who use LBIS applications on their mobile device (Cheng et al., 2013). This might be attributed to the cognitive resilience that allows users to quickly focus on the information, rather than its function or the technological details of LBIS, amongst those who had prior experience with LBIS. This implies that prior experience could constitute a central part of knowledge that is likely to facilitate speedy judgment on the location information shared on Facebook. However, it is not clear whether such recall is positively associated with the credibility evaluation of the location information.

In addition to one's prior experience with Check In on Facebook, it is also important to scrutinise how likely users are to use a mobile phone. Since location check-ins on Facebook mostly happen via mobile phones, the original capability of using a mobile phone as a medium for the sharing should come into play with one's cognitive processing of location information along with the actual experience with the affordance of this feature on Facebook. The previous literature suggests that one's level of skill with a mobile phone would make a difference in the amount of information acquisition. Suki and Suki (2007) found that heavy mobile users, assumably more apt to use mobile phones, sought, accessed and subscribed to more mobile content than light users did. In other words, having sufficient skills for mobile phone use gave users more chances to absorb information, as they did not need to spend time learning how to use it, which typically happened with regard to other media technology as well (e.g. computers, the internet) (van Deursen, 2012).

Therefore, akin to the logic of the potential moderating effect of prior experience with the activity on the credibility assessment with location information provided by Facebook friends, mobile phone skills and users' perceived competence with the location check-in function on Facebook could also switch users' cognitive mode from (source) cue-dependent to content-focused or vice versa, hence decreasing or increasing the likelihood of 
instant positive evaluations of the information. If users are not very competent in mobile phone use, they need to devote more cognitive energy to figure out what the feature of Check In on Facebook is and what purpose such location information is intended to fulfil. As a result of dispersed mental labour for both the technological feature and information processing, attitudes and credibility assessments for the location information could be less positive when users are not very efficacious with their skill set for mobile use. However, one might also argue that most young mobile users are equipped with sufficient knowledge and comfort with the Facebook interface. Hence, mobile phone competence might not play a critical role in influencing a Facebook user's cognitive processing of location information that the user's friends offer onFacebook.

Thus, it is assumed that prior experience with LBIS on Facebook and users' competence with mobile phone use would make a difference in the original relationship between the friendship tie and perceived credibility of and attitude towards the location information. However, the direction of the perceived credibility and attitude as a result of the moderating effects of individual users' capability to adopt a new technological affordance (i.e. checking in at locations) to their daily lifestyle is not clearly predicted.

H2a. Users' prior experience with LBIS on Facebook will moderate the relationship between the friendship tie and the users' attitudes towards and perceived credibility of the location information that they find on their friends' Facebook feeds.

$H 2 b$. Users' mobile phone competence will moderate the relationship between the friendship tie and the users' attitudes towards and perceived credibility of the location information that they find on their friends' Facebook feeds.

\section{Method}

A total of 255 undergraduate students were recruited from two institutions, one of which is located in the Midwestern region $(n=170)$ whilst the other is located on the East Coast $(n=85)$. No difference was found for any of the measured variables in the sample groups of the two institutions. Whilst all of the students had a Facebook account, $42 \%$ of the students had not checked in at locations on Facebook before. Students checked their Facebook feeds for about $1 \mathrm{~h}$ per day, although they reported that they used their mobile phone for about $4 \mathrm{~h}$ per day on average. Fifty-one percent of the students were females, and white was the dominant race in the sample, constituting $87 \%$. The average age of the sample was 20 years old $(\mathrm{SD}=1.30)$.

\subsection{Survey procedure}

Students completed a self-instructed online survey following the instructions inserted in the survey. Upon submitting their name and the date of participation as an agreement on the implied consent form, students proceeded with a series of questions about their prior LBIS experience, including Facebook Check In, and their level of competency with mobile phone use. After they submitted their responses to these questions, the students were instructed to complete a small task on their own Facebook account page by logging into their Facebook account in a separate internet browser. The instructions for the task requested that the students review their Facebook feeds from the last three days and check if any of their friends tagged locations. Students were asked to review their Facebook feed whilst they completed the rest of the questionnaire, which measured the primary measured variables for the present study, including friendship strength, attitudes towards the location information shared by those friends and the perceived credibility of the location information. This self-instructed survey had proven to be a valid method in a previous study for a sample of high-school-aged mobile phone users (Cingel and Sundar, 2012). 


\subsection{Measured variables}

Prior experience with location check-ins on Facebook was measured by a single item that asked whether participants had tagged locations on their Facebook account via mobile phone or not. For the primary purpose of this study, 108 cases were excluded when the students indicated that they did not find any friends who shared location information on Facebook. Therefore, the main analysis used 106 student cases $(61 \%)$ for the group with prior experience and 69 cases (39\%) for the group with no experience with LBIS on Facebook.

Friendship strength was measured on a scale of five items that operationalised relationship strength based on "the amount of time, the emotional intensity, the intimacy and the reciprocal services", which would vary in relationships (Gilbert and Karahalios, 2009, p.212; Granovetter, 1973). The five items yielded a high level of inter-item reliability $(\alpha=0.82)$.

Mobile phone competence ${ }^{1}$ was measured by asking students about their proficiency level of the skill set for mobile phone use (Bakke, 2010). Twenty-four items meticulously assessed how students felt about their mobile phone usage skills, including message composition, technological adaption and efficacy $(\alpha=0.96)$.

Last, a scale consisting of 11 adjectives (i.e. relevant, timely, informative, entertaining, enjoyable, pleasing, irritating [reverse coded], insulting [reverse coded], overwhelming [reverse coded], likable and positive; $\alpha=$ 0.82 ) measured users' attitudes towards the location information. Another scale of three adjectives (i.e. credible, trustworthy and believable) measured the perceived credibility of the location information shared by Facebook friends $(\alpha=0.93)$. These attitudes and credibility measurement items were adopted and modified from a scale used to measure the attitudes and credibility of mobile advertising (Lee, Hsieh and Huang, 2011). The measurement items for mobile phone competence and friendship tie strength are available in the Appendix.

\section{Results}

A multivariate analysis of variance (MANOVA) of friendship tie strength and prior LBIS on Facebook was performed to determine the main effects of the variable and/or interaction effects between the variables on attitudes towards and perceived credibility of the location information that friends tagged (H1s and H2a). A significant main effect of friendship tie strength $\left(F_{(2,170)}=10.23, p<0.001\right)$ and a significant main effect of prior experience with LBIS on Facebook $\left(F_{(2,170)}=3.85, p<0.05\right)$ were found on two dependent variables (Wilks' $\Lambda=0.84, p<0.001$ ). Post-hoc general linear model analyses indicated that the greater the tie strength was with their friends, the more positive their attitudes were towards the location information tagged by these friends $(\beta=0.24)$ and the more credible the information was perceived as being $(\beta=0.26)$. Students who had checked in at locations on Facebook also reported more positive attitudes and greater perceived credibility of the location information that friends tagged (attitude: $M=4.02, \mathrm{SD}=0.09$; perceived credibility: $M=4.28$, $\mathrm{SD}=0.15$ ) than those who had not engaged in this activity on Facebook (attitude: $M=3.64, \mathrm{SD}=0.11$; perceived credibility: $M=3.76, \mathrm{SD}=0.18$ ). Thus, $\mathrm{H} 1 \mathrm{a}$ and $\mathrm{H} 1 \mathrm{~b}$ were supported, whilst $\mathrm{H} 2 \mathrm{a}$ was not supported. Another MANOVA of friendship tie strength and mobile phone competence was performed to see if any interaction effects between the two variables would exist on the two dependent variables. A significant main effect of friendship tie strength $\left(F_{(2,170)}=10.56, p<0.001\right)$ and a significant interaction effect between the two variables $\left(F_{(2,170)}=4.57, p<0.05\right)$ were found on two dependent variables (Wilks' $\Lambda=0.82, p<$ 0.001). Post-hoc general linear model analyses still supported H1s regarding the positive influence of friendship tie strength on attitudes and perceived credibility. The interaction effects between friendship tie strength and users' mobile phone competence supported $\mathrm{H} 2 \mathrm{~b}$ such that the positive relationship between the friendship tie and attitudes and perceived credibility was still true amongst those who showed higher competence with mobile phone use. However, such a relationship was not found amongst those who showed lower competence with mobile phone use; hence, no relationship was shown between the friendship tie and dependent variables 
(Figure 1).

Figure 1 Two-way interaction effect of friendship tie and mobile phone competence on perceived credibility of (left) and attitudes towards (right) friends' location information
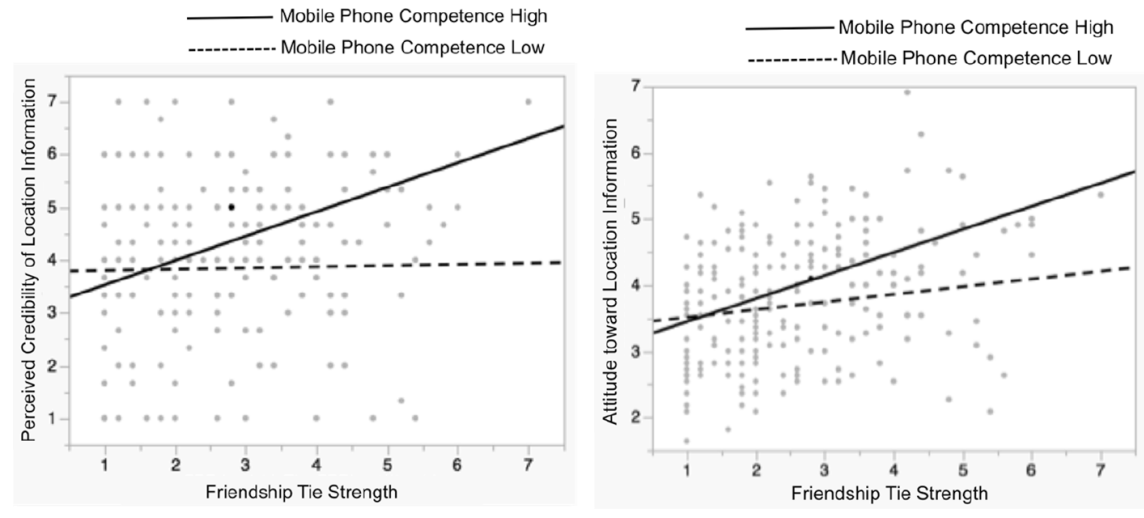

\section{Discussion}

The previous literature has pointed out a vital role of interpersonal relationships in sales and marketing (Crosby, Evans and Cowles, 1990). Such a positive influence of the interpersonal relationship on the marketing is attributed to the importance of trust between brands and potential buyers for purchasing behaviour (Doney and Cannon, 1997). In fact, the development of trust does not always require direct experience with brands. Given a firm and interdependent relationship amongst individuals in a group, experiences with brands transfer from one to another through distribution channels of information (Donny and Cannon, 1997, p.36; Lin, Paragas and Bautista, 2016). In other words, it is quite likely that people develop positive impressions of a business location that their Facebook friends tag as an expression of their pleasant experience with the business. Findings from the present study evidence a great likelihood of the strong influence of friendship on one's assessment of pseudoadvertising. However, this is subject to one's prior experience and skill with technological affordance.

\subsection{Friendship as an invisible trust heuristic}

The present study found a positive relationship between the friendship strength and cognitive evaluations of location information on Facebook. As guided by the PKM, the absence of persuasive intent by advertising agents in location information shared by friends on Facebook is likely to drive positive evaluations (van Noort, Antheunis and Reijmersdal, 2012; Xu, 2014). Specifically, the support of the first set of hypotheses evidenced the possibility of cue-based information processing triggered by the source of location information (i.e. Facebook friends, especially close friends). However, the lack of mobile phone competence decreased this cuedependent information processing because of possible cognition dispersion (Yang, Kim and Yoo, 2013; Suki and Suki, 2007) (Figure 1). As an aggregated information platform, Facebook is now an information centre for mobile users (Counts and Fisher, 2010). However, information overload is still a typical phenomenon on Facebook (Koroleva, Krasnova and Günther, 2010), and it may prevent Facebook users who access the platform via their mobile phones from enjoying a quick manner of information processing.

The findings of the present study showcased that source credibility, which is considered a significant cue for instant information processing (Johnson and Kaye, 2015; Petty and Cacioppo, 1986), seems naturally to transfer to information credibility in the case of LBIS. Even though the source credibility represented by the strength of friendship is not identifiable in a physical form anywhere on Facebook, the source cue was likely to boost positive evaluations of location information, presumably via cue-dependent processing as the ELM (Petty and Cacioppo, 1986). As the ELM also hypothesised, individual differences that contribute to the likelihood of cognitive dispersion must be considered in the effects of source cues on the information evaluations (Petty and 
Caccioppo, 1986). For instance, Gurrea, Orús and Flavián (2013) found that product quality seals (e.g. "recommended product", "top sales", or "special offer", p.16) led to elaboration of information processing amongst users of online product reviews when the users were naturally inclined to carefully scrutinise information (i.e. high need for cognition). For those who did not usually employ cognitive elaboration (i.e. low need for cognition), those seals greatly contributed to their cue-dependent processing. Likewise, "visible" cues typically direct information receivers to an experience by activating mental shortcuts, leading to a quick, and likely positive, judgement. However, this instant information assessment is no longer valid for those who genuinely allocate their cognitive efforts to in-depth processing of the information (Kim, Kim and Besley, 2013). This is not the case, however, with location information shared by friends. The null finding of the present study regarding the moderating effect of prior experience corroborated that people's trust in their friends automatically operated as an invisible cue to trigger cue-dependent processing, so they evaluated the location information shared by the friends in a positive light.

In addition, this invisible trust cue of friendship is worth being noted along with the simplicity of the location information shared on Facebook. Wang, Yu and Wei (2012) suggested that talking about products with friends on social media would increase positive attitudes towards the products and, hence, intention to purchase the products. This relationship would be pronounced when users strongly identified those friends as "close". Consistent with this previous study's finding, the current study found that stronger friendships led to more positive attitudes towards and greater perceived credibility of the location information. However, the present study's finding is unique in that simple exposure to succinct information, typically the name of a business, still showed the predicted direction of psychological perception without direct conversations about the location experience with the friends.

Furthermore, it should be noted that the positive evaluation of the simple location information on Facebook was possible because Facebook users did not need to seriously review the business location that their friends tagged on Facebook, but simply formed their attitudes instead. Baek, Ahn and Choi (2012) found that users of an ecommerce website (i.e. Amazon.com) were likely to activate cue-dependent processing for quality judgement when reading online reviews by focusing on available information cues such as star rating reviews, the number of reviews and review helpfulness when searching for experienced goods (e.g. baby books) or inexpensive goods (e.g. goods below \$100). However, the site users engaged in information processing in an elaborated fashion based on the actual content of the reviews or product descriptions when considering purchasing search goods (e.g. USB drives) or expensive goods (e.g. goods above \$100). Thus, before encountering the actual moment of decision, whether visiting for dining, travelling or lodging, Facebook users' processing of location information is likely to rely on friendship as a trust cue, which is still crucial to marketing.

\subsection{Experience with location-based information sharing as a precursor of reciprocity and social influence in the} realm of social media

Unlike the prediction of a moderating effect of one's prior experience with LBIS on Facebook, the present study simply found a positive effect of it on Facebook. This finding may offer pragmatic insights into advertisers and marketing practitioners with regard to LBIS as behavioural contagion (Polansky, Lippitt and Redl, 1950) on Facebook and other social media for its persuasive effects. In other words, prior experience with LBIS was not a precursor of the likelihood of cognitive elaboration; instead, it might operate as a precursor of social influence, as prior experience showed its main effect on the attitudes towards and perceived credibility of location information in the current study. The previous literature explicated tie strength in the realm of exchanging social support (Granovetter, 1973). Like the positive effect of a strong relationship tie on users' evaluations of location information, experiences with sharing would be likely to induce positive psychology, especially when users also benefit from the information and support shared by other users on social media platforms. In this sense, prior experience with LBIS on Facebook generates positive psychological reactions towards the outcome of the same information-sharing activity of friends based on the principle of reciprocity. Those who have checked in 
at locations previously on Facebook might have done so to promote the quality of their experience with the locations, and so they know that their friends wanted to share locations for the same reason.

Reciprocity is a strong reinforcement of positive attitude formation amongst information sharers and social supporters (Krishnan and Carment, 1979). Reciprocal interactions positively contribute to indirect advertising effects through behavioural contagion, especially in mass interactions in which a recipient's role becomes "more like that of the actor or initiator". The exchange of information and social support as a result of behavioural contagion would be made without the actor's visible intention to influence others during social interactions (Polansky, Lippitt and Redl, 1950, p.322). For instance, Bond et al. (2012) suggested that a strong influence of close relationships would exist for Facebook user behaviour in the context of voting and political decisionmaking processes. The study found that users read a political message more when they found their friends on Facebook viewing the same political message than when they found that their friends did not read the message. This effect was observed only in the group that reported solid friendships with their Facebook friends. Likewise, when Facebook users already engage in LBIS, their habitual action of LBIS will carry a positive influence to evaluations of the location information shared by their friends as a function of social influence, which anticipates a domino effect of an indirect, interpersonal advertising strategy.

Although the present study found evidence of meaningful theoretical and practical implications, it is not free from study limitations. First, the present study assumed, rather than directly measuring, the perceived persuasion intent whilst it applied the PKM as a theoretical foundation. Ontologically, it was obvious that less persuasion intent was detected in location information shared by friends on Facebook than information advertised by businesses because of the unique presentation of information via location check-ins on Facebook compared to traditional forms of advertisements. However, one might raise the question that it would not be clear why Facebook users showed positive reactions to the location information shared by their friends; could it be explained by the deficit of persuasion intent because their friends, not business advertisers, shared that information, or solely by the cuing effect of the information source? In other words, the persuasion intent might still be detected, but Facebook users did not mind the promotional intention contained in location information as long as their close friends shared it. This theoretical ambiguity calls for careful investigation to unpack the main relationship between the friendship tie and cognitive evaluations of locationinformation.

In addition, the present study did not parcel out the depth of location information that study participants reviewed. Most of the location information shared on Facebook include the name of the business and sometimes a succinct comment on the tagged location, along with the more recent addition of aggregated reviews via Google with star ratings of the business. There might be a different degree of the information depth across tagged locations, which vary depending on the additional information provided for the location besides the name of the business. Furthermore, positive experiences with the locations tagged on Facebook were assumed, but not precisely measured, in the current study since the participants were not asked to review specific nuances of those location check-in postings appearing in their Facebook feeds. Similarly, another factor that might influence evaluations of location information would be proximity of the locations to users. Perceived spatial distance is one of the critical factors that would affect evaluations of location information (Fujita et al., 2006). All of these aforementioned study limitations leave room for future research.

\section{References}

Baek, H., Ahn, J. and Choi, Y. (2012) 'Helpfulness of online consumer reviews: readers' objectives and review cues', International Journal of Electronic Commerce, Vol. 17, No. 2, pp.99-126.

Bakke, E. (2010) 'A model and measure of mobile communication competence', Human Communication Research, Vol. 36, No. 3, pp.348-371.

Bond, R.M., Fariss, C.J., Jones, J.J, Kramer, A.D., Marlow, C., Settle, J.E. and Fowler, J.H. (2012) 'A 61million-person experiment in social influence and political mobilization', Nature, Vol. 489, No. 7415, pp.295-298. 
Brown, J., Broderick, A.J. and Lee, N. (2007) 'Word of mouth communication within online communities: conceptualizing the online social network', Journal of Interactive Marketing, Vol. 21, No. 1, pp.2-20.

Chang, C.W. and Heo, J. (2014) 'Visiting theories that predict college students' self-disclosure on Facebook', Computers in Human Behaviour, Vol. 30, pp.79-86.

Chang, K.T.T., Chen, W. and Tan, B.C.Y. (2012) 'Advertising effectiveness in social networking sites: social ties, expertise, and product type', Engineering Management, IEEE Transactions, Vol. 59, No. 4, pp.634643.

Cheng, H., Arefin, M.S., Chen, Z. and Morimoto, Y. (2013) 'Place recommendation based on users check-in history for location-based services', International Journal of Networking and Computing, Vol. 3, No. 2, pp.228-243.

Cingel, D. and Sundar, S.S. (2012) 'Texting, techspeak, and tweens: the relationship between text messaging and English grammar skills', New Media and Society, Vol. 14, No. 8, pp.1304-1320.

Counts, S. and Fisher, K.E. (2010) 'Mobile social networking as information ground: a case study', Library \& Information Science Research, Vol. 32, No. 1, pp.98-125.

Crosby, L.A., Evans, K.R. and Cowles, D. (1990) 'Relationship quality in services selling: an interpersonal influence perspective', Journal of Marketing, Vol. 54, No. 3, pp.64-81.

Dhar, S. and Varshney, U. (2011). 'Challenges and business models for mobile location-based services and advertising', Communications of the ACM, Vol. 54, No. 5, pp.121-128.

Doney, P.M. and Cannon, J.P. (1997) 'An examination of the nature of trust in buyer-seller relationships', Journal of Marketing, Vol. 61, No. 2, pp.35-51.

Donny, P.M. and Cannon, J.P. (1997). 'An examination of the nature of trust in buyer-seller relationships', Journal of Marketing, Vol. 61, No. 2, pp.35-51.

Fogg, B.J. (1999) 'Persuasive technologies - now is your chance to decide what they will persuade us to doand how they'll do it', Communications of the ACM, Vol. 42, No. 5, pp.26-29.

Friestad, M. and Wright, P. (1994) 'The persuasion knowledge model: how people cope with persuasion attempts', Journal of Consumer Research, Vol. 21, No. 1, pp.1-31.

Fujita, K., Henderson, M.D., Eng, J., Trope, Y. and Liberman, L. (2006) 'Spatial distance and mental construal of social events', Psychological Science, Vol. 17, No. 4, pp.278-282.

Gilbert, E. and Karahalios, K. (2009) 'Predicting tie strength with social media', Proceedings of CHI '09 of the SIGCHI Conference on Human Factors in Computing Systems, April 4-9, 2009, Boston, MA, pp.211-220.

Granovetter, M.S. (1973) 'The strength of weak ties', The American Journal of Sociology, Vol. 78, No. 6, pp.1360-1380.

Gruen, T.W., Osmonbekov, T. and Czaplewski, A.J. (2006) 'eWOM: the impact of customer-to-customer online know-how exchange on customer value and loyalty', Journal of Business Research, Vol. 59, No. 4, pp.449456.

Gurrea, R., Orús, C. and Flavián, C. (2013) 'The role of symbols signalling the product status on online users' information processing', Online Information Review, Vol. 37, No. 1, pp.8-27.

Hennig-Thurau, T., Gwinner, K.P., Walsh, G. and Gremler, D.D. (2004) 'Electronic word-of-mouth via consumer-opinion platform: what motivates consumers to articulate themselves on the Internet?', Journal of Interactive Marketing, Vol. 18, No. 1, pp.38-52.

Jansen, B.J., Zhang, M., Sobel, K. and Chowdury, A. (2009) 'Twitter power: tweets as electronic word of mouth', Journal of the American Society for Information Science and Technology, Vol. 60, No. 11, pp.2169-2188.

Jeong, E. and Jang, S.S. (2011) 'Restaurant experiences triggering positive electronic word-of-mouth (eWOM) motivations', International Journal of Hospitality Management, Vol. 30, No. 2, pp.356-366.

Johnson, T.J. and Kaye, B.K. (2015) 'Reasons to believe: influence of credibility on motivations for using social networks', Computers in Human Behavior, Vol. 50, pp.544-555.

Karimi, B. and Yektaei, M.H. (2015) 'Location recommendation based on location-based social networks for entertainment services', ACSIJ Advances in Computer Science: an International Journal, Vol. 4, No. 1, 
pp.55-64.

Kim, H-S. (2016) 'What drives you to check in on Facebook? Motivations, privacy concerns, and mobile phone involvement for location-based information sharing', Computers in Human Behavior, Vol. 54, pp.397-406.

Kim, S., Kim, J. and Besley, J.C. (2013) 'Pathways to support genetically modified (GM) foods in South Korea: deliberate reasoning, information shortcuts, and the role of formal education', Public Understanding of Science, Vol. 22, No. 2, pp.169-184.

Koroleva, K., Krasnova, H. and Günther, O. (2010) 'Stop spamming me!: exploring information overload on Facebook', Proceedings of AMCIS 2010. Paper 447. Available at: http://aisel.aisnet.org/amcis2010/447. Access date: October 10, 2014.

Krishnan, L. and Carmnet, D.W. (1979) 'Reactions to help: reciprocity, responsibility and reactance', European Journal of Social Psychology, Vol. 9, No. 4, pp.435-439.

Lee, C-C., Hsieh, M-C. and Huang, H-C. (2011) 'The influence of mobile self-efficacy on attitude towards mobile advertising', Advances in Information Science and Service Science, Vol. 3, No. 3, pp.100-108.

Lin, T.T.C., Paragas, F. and Bautista, J.R. (2016). 'Determinants of mobile consumers' perceived value of location-based advertising and user responses', International Journal of Mobile Communications, Vol. 14, No. 2, pp.99-117.

Lindqvist, J., Cranshaw, J., Wiese, J., Hong, J. and Zimmerman, J. (2011) 'I'm the mayor of my house: examining why people use foursquare - a social-driven location sharing application', Proceedings of the SIGCHI Conference on Human Factors in Computing Systems, May 7-12, 2011, Vancouver, Canada, pp.2409-2418.

Noulas, A., Scellato, S., Mascolo, C. and Pontil, M. (2011) 'An Empirical Study of Geographic User Activity Patterns in Foursquare, ICWSM 11, Barcelona, Spain, pp.570-573.

Nov, O., Naaman, M. and Ye, C. (2010) 'Analysis of participation in an online photo-sharing community: a multidimensional perspective', Journal of the American Society for Information Science and Technology, Vol. 61, No. 3, pp.555-566.

Petreascu, M. and Korgaonkar, P. (2011) 'Viral advertising: definitional review and synthesis', Journal of Internet Commerce, Vol. 10, No. 3, pp.208-226.

Petty, R.E. and Cacioppo, J.T. (1986) 'The elaboration likelihood model of persuasion', in Berkowitz, L. (Ed.): Advances in Experimental Social Psychology, Vol. 19, Academic Press Inc., Orlando, Florida, USA, pp.123-205.

Pew Internet Research. (2013) Mobile Technology Fact Sheet. [online] Fact Sheet http://www.pewinternet.org/fact-sheets/mobile-technology-fact-sheet/ (access 29 March 2014).

Pew Research Center. (2010) Millennials: a Portrait of Generation Next. Available at: http://www.pewsocialtrends.org/files/2010/10/millennials-confident-connected-open-to-change.pdf (access 20 March 2014).

Polansky, N., Lippitt, R. and Redl, F. (1950) 'An investigation of behavioural contagion in groups', Human Relations, Vol. 3, No. 4, pp.319-348.

Pontes, T., Vasconcelos, M., Almeida, J., Kumaraguru, P. and Almeida, V. (2012) 'We know where you live: privacy characterization of foursquare behaviour', Proceedings of the 2012 ACM Conference on Ubiquitous Computing, ACM, Sep 5-Sep 8, 2012, Pittsburgh, PA, pp.898-905.

Suki, N.M. and Suki, N.M. (2007) 'Mobile phone usage for m-learning: comparing heavy and light mobile phone users', Campus-wide Information Systems, Vol. 24, No. 5, pp.355-365.

Sundar, S.S. (2008) 'The MAIN model: a heuristic approach to understanding technology effects on credibility', in Metzger, M.J. and Flanagin, A.J. (Eds.): Digital media, youth, and credibility. The MIT Press, Cambridge, MA, pp.72-100.

van Deursen, A.J.A.M. (2012) 'Internet skill-related problems in accessing online health information', International Journal of Medical Informatics, Vol. 8, No. 1, pp.61-72.

van Noort, G., Antheunis, M.L. and van Reijmersdal, E.V. (2012) 'Social connections and the persuasiveness of viral campaigns in social network sites: persuasive intent as the underlying mechanism', Journal of Marketing Communications, Vol. 18, No. 1, pp.39-53. 
Wang, S.S. and Stefanone, M.A. (2013) 'Showing off? Human mobility and the interplay of traits, selfdisclosure, and Facebook check-ins', Social Science Computer Review, Vol. 31, No. 4, pp.437-457.

Wang, X., Yu, C. and Wei, Y. (2012) 'Social media peer communication and impacts on purchase intentions: a consumer socialization framework', Journal of Interactive Marketing, Vol. 26, No. 4, pp.198-208.

Waters, S. and Ackerman, J. (2011) 'Exploring privacy management on Facebook: motivations and perceived consequences of voluntary disclosure', Journal of Computer-Mediated Communication, Vol. 17, No. 1, pp.101-115.

Wathen, C.N. and Burkell, J. (2002) 'Believe it or not: factors influencing credibility on the web', Journal of American Society for Information Science and Technology, Vol. 53, No. 2, pp.134-144.

Wilson, M. (2012) 'Location-based services, conspicuous mobility, and the location-aware future', Geoforum, Vol. 43, No. 6, pp.1266-1275.

$\mathrm{Xu}$, Q. (2014) The Persuasiveness of Viral Advertising on Social Networking Site: Exploring the Effects of Tie Strength and Message Publicity, Paper presented at the International Communication Association, May 2014. Seattle, WA.

Yang, B., Kim, Y. and Yoo, C. (2013) 'The integrated mobile advertising model: the effects of technology-and emotion-based evaluations', Journal of Business Research, Vol. 66, No. 9, pp.1345-1352.

Yoo, C.Y. (2009) 'The effects of persuasion knowledge on click-through of keyword search ads: moderating role of search task and perceived fairness', Journalism and Mass Communication Quarterly, Vol. 86, No. 2, pp.401-418.

\section{Note}

1 Median $(5.54, \mathrm{SD}=0.94)$ split was performed to construct a categorical variable for the sake of visualising an interaction effect between the friendship tie and mobile phone competence on attitudes towards and perceived credibility of the location information friends tagged on Facebook. 
Appendix

\section{Measurement items}

Mobile phone competence (Bakke, 2010)

My mobile phone text messages are written in a confident style.

I know I can learn to use new mobile phone technologies when they come out. I feel good about my mobile phone conversations.

I am very familiar with the features on a mobile phone. I use an assertive style when writing a text message.

I choose which mobile phone feature (i.e. voice, text, and picture messages, etc.) to communicate with based on the extent to which I need to get some "back and forth", "give and take", and interchange of ideas.

I quickly figure out how to use new features on a mobile phone. I enjoy communicating using mobile phones.

I choose which mobile phone feature (i.e. voice, text, and picture messages.) to communicate with based on how personal or intimate the information in the message is.

I rely heavily upon my mobile phone for getting me through each day. I display a lot of certainty in the way I write my text messages.

I am confident that I will learn how to use any new features that are due to come out. If I can use a mobile phone for communicating, I tend to.

I make sure my objectives are emphasised in my mobile phone text messages. I consistently achieve my goals in mobile phone interactions.

I enjoy my mobile phone interactions with others.

My mobile interactions are effective in accomplishing what I set out to accomplish.

I feel completely capable of using almost all the features available on a mobile phone.

I use a mobile phone as means of communication almost constantly.

I choose which mobile phone feature (i.e. voice, text, and picture messages.) to communicate with based on how much information is involved in the message I need to communicate.

I am a heavy user of mobile phone communication.

I am generally pleased with my mobile phone interactions.

I am very articulate and vivid in my mobile phone text messages. I am effective in my mobile phone conversations with others.

Friendship tie strength (Gilbert and Karahalios, 2009)

The Facebook friends who tagged locations and myself are very close.

I feel very comfortable with asking these Facebook friends who tagged locations to borrow $\$ 100$ or more.

These Facebook friends who tagged locations would be very helpful if I were looking for a job.

I would be very upset if these Facebook friends who tagged locations unfriended me.

It would be very important to bring these Facebook friends who tagged locations to another social networking site if I left Facebook for the new site. 